\title{
Biodistribution and radiation dosimetry of radioiodinated hypericin as a cancer therapeutic
}

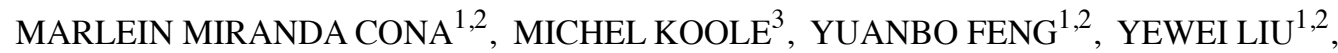 \\ ALFONS VERBRUGGEN $^{4}$, RAYMOND OYEN ${ }^{1}$ and YICHENG NI ${ }^{1,2}$ \\ ${ }^{1}$ Department of Imaging and Pathology, ${ }^{2}$ Molecular Small Animal Imaging Centre/MoSAIC, Faculty of Medicine, \\ Biomedical Sciences Group, KU Leuven; ${ }^{3}$ Nuclear Medicine Section, University Hospitals Group, UZ Leuven; \\ ${ }^{4}$ Faculty of Pharmaceutical Sciences, Biomedical Sciences Group, KU Leuven, Leuven, Belgium
}

Received September 10, 2013; Accepted November 1, 2013

DOI: $10.3892 /$ ijo.2013.2217

\begin{abstract}
Iodine-131-labeled monoiodohypericin ( $\left.{ }^{131} \mathrm{I}-\mathrm{Hyp}\right)$ is a necrosis avid compound used as a complementary anticancer agent. Herein, the biodistribution in rats with re-perfused partial liver infarction (RPLI) was used to estimate its human internal radiation dosimetry. Iodine-123-labeled monoiodohypericin ( $\left.{ }^{123} \mathrm{I}-\mathrm{Hyp}\right)$ as a safer surrogate for ${ }^{131} \mathrm{I}$-Hyp was prepared with iodogen as oxidant. Determination of radiochemical yield and purification was performed by high performance liquid chromatography (HPLC). To control aggregation, the formulation was macroscopically and microscopically examined. Biodistribution of ${ }^{123} \mathrm{I}$-Hyp was studied in RPLI rats $(\mathrm{n}=18)$ at 4,24 and $48 \mathrm{~h}$ post-injection. Tissue gamma counting (TGC), autoradiography and histology were performed. Dosimetry of ${ }^{131} \mathrm{I}$-Hyp in hepatic necrosis and in normal human organs was estimated using biodistribution data of ${ }^{123} \mathrm{I}-\mathrm{Hyp}$, the Organ Level Internal Dose Assessment/Exponential Modeling (OLINDA/EXM ${ }^{\circledR}$ ), a sphere model and male and female phantoms. A radiochemical yield of $95 \%$ was achieved in labeling of ${ }^{123} \mathrm{I}-\mathrm{Hyp}$ with a radiochemical purity of $99 \%$ after HPLC purification. In the Hyp added formulation, no macroscopic but minimal microscopic aggregation was observed. By TGC, selective accumulation in hepatic infarction and low uptake in viable liver of ${ }^{123} \mathrm{I}-\mathrm{Hyp} / \mathrm{Hyp}$ were detected, as confirmed by autoradiography and histology. Significantly higher doses of ${ }^{131} \mathrm{I}$-Hyp were delivered to necrotic (276-93,600 $\mathrm{mGy} / \mathrm{MBq})$ than to viable (4.2 $\mathrm{mGy} / \mathrm{MBq})$ liver $(\mathrm{P}<0.05)$. In normal organs, ${ }^{123} \mathrm{I}-\mathrm{Hyp}$ was eliminated within $24 \mathrm{~h}$ except for relatively high levels in the lungs and thyroid. Hepatobiliary elimination was a major pathway of ${ }^{123} \mathrm{I}-\mathrm{Hyp}$ causing high activity in the intestines. For both genders, dosimetry showed the longest residence time of ${ }^{131} \mathrm{I}$-Hyp in the remainder, followed by the lungs, intestines and thyroid. The
\end{abstract}

Correspondence to: Professor Yicheng Ni, Radiology Section, University Hospitals, K.U. Leuven, Herestraat 49, B-3000 Leuven, Belgium

E-mail: yicheng.ni@med.kuleuven.be

Key words: OncoCiDia, ${ }^{123 / 131}$ I-Hyp, necrosis, rats, re-perfused partial liver infarction, biodistribution, dosimetry highest absorbed radiation dose was seen in necrotic tissues and the shortest residence times and lowest absorbed radiation dose were found in the brain. ${ }^{131}$ I-Hyp selectively delivers higher radiation dose to necrosis compared with the rest of the body. Among normal organs, thyroids, lungs and intestines receive considerable radiation dose, which deserves cautious attention in developing this anticancer approach.

\section{Introduction}

Solid tumors account for $90 \%$ of all known cancers (1). Treatment options depend on location, grade and stage of the tumor as well as the performance status of the patient. Up to now, surgery, chemotherapy and external beam radiation therapy have constituted the conventional workhorses for treating cancers. However, surgery may suffer from impaired efficacy due to invasion and metastasis of malignant cells, whereas chemotherapy and radiotherapies may negatively impact on normal organs or tissues.

Systemic targeted radiotherapy (STR) relies on high-energy radioactive sources systemically delivered to the tumor and has shown promise in the management of certain malignancies. Targeted therapy agents have been increasingly available for clinical applications such as radioactive iodine in the form of iodide to treat thyroid cancer (2); strontium-89 chloride (Metastron ${ }^{\circledR}$ ) for pain palliation in skeletal metastases (3); iodine-131 metaiodobenzylguanidine $\left({ }^{131} \mathrm{I}-\mathrm{MIBG}\right)$ for neural crest-derived tumors $(4,5)$; radioactive microspheres for radioembolization of liver cancer, indium-111 ( $\left.{ }^{111} \mathrm{In}\right)$, yttrium-90 $\left({ }^{90} \mathrm{Y}\right)$ and lutetium-177 $\left({ }^{177} \mathrm{Lu}\right)$ bound to somatostatin derivatives for neuroendocrine tumors (NETs) $(7,8)$ and the most recently FDA-approved Radium-223 chloride (Alpharadin, Xofigo) for osteoblastic metastases in patients with aggressive prostate cancer (9). However, little progress has been made in the fight against vast solid tumors with diverse histological patterns and disorganized angiogenesis (10). Once carcinogenesis occurs, tumor cells are turned on to be resistant to biology based therapies due to the escape mechanisms facilitated by the unpredictable intrinsic mutations or overlapping molecular pathways $(11,12)$.

OncoCiDia is a newly emerging strategy intended to improve cancer treatment or cure. Based on an unconven- 


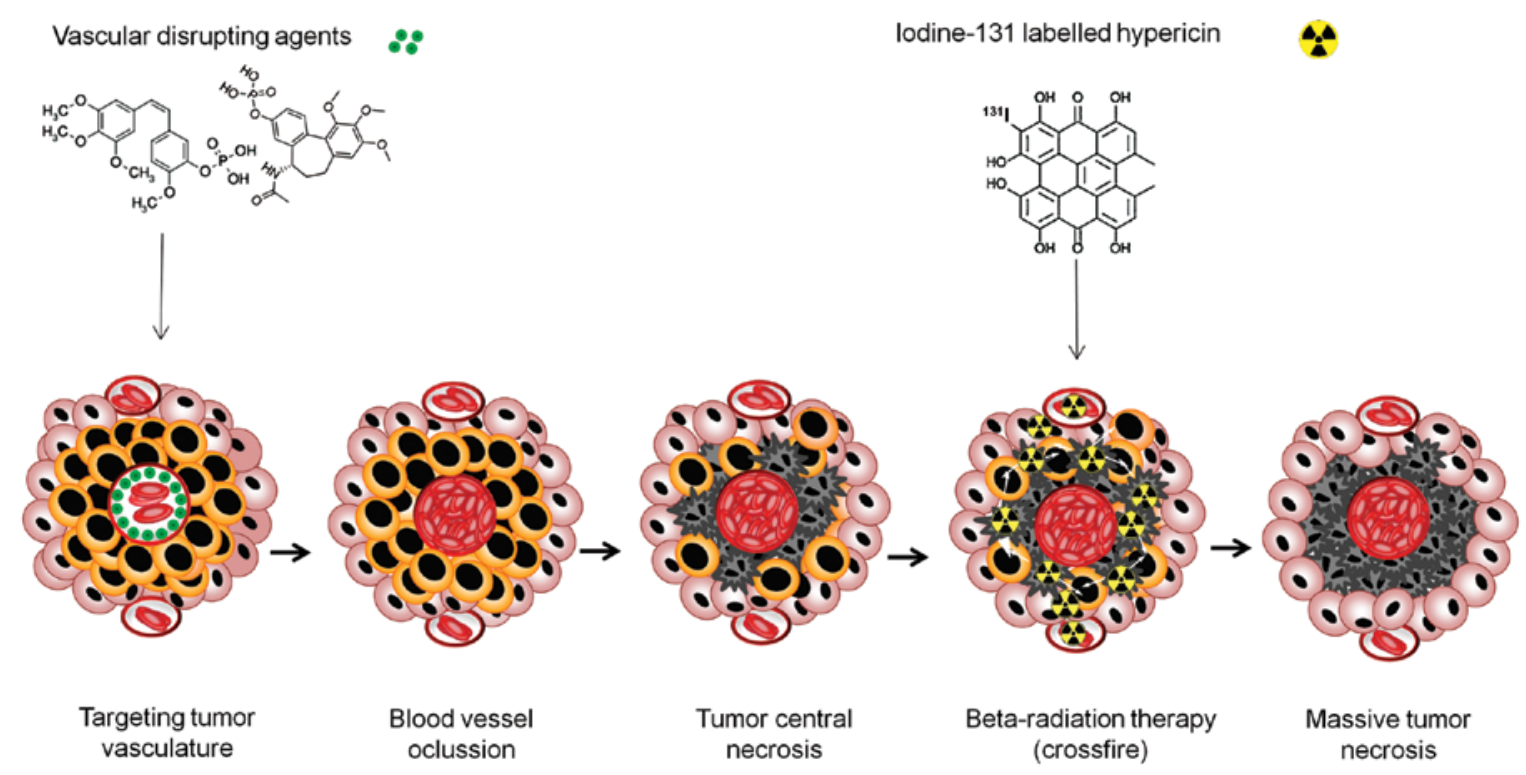

Normal cells

Blood vessels

Cancer cells

Dead cells

Figure 1. Schematic representation of the dual-targeting anticancer approach OncoCiDia. The initial administration of a vascular disrupting agent (VDA) selectively causes blood vessel occlusion within tumor and subsequent central necrosis. The necrosis avid compound iodine-131 labelled hypericin ( $\left.{ }^{131} \mathrm{I}-\mathrm{Hyp}\right)$ is then systemically delivered and it accumulates in the necrotic sites to eradicate residual cancer cells through crossfire beta radiation effect.

tional soil-to-seeds principle, this approach aims at two stable intratumoral structures intimately linked to tumor cells in location and functionality (13). The initial delivery of a vascular disrupting agent (VDA) selectively shut down the tumor blood vessels by destroying the immature tumor endothelium, leading to ischemic tumor necrosis. However, a rim of residual viable tumor cells always survives as the seeds for cancer re-growth. Thus, a necrosis avid agent hypericin (Hyp) carrying the betaemitter iodine-131 is systemically delivered and specifically accumulates at intratumoral necrosis newly created by the VDA. It lethally irradiates the adjacent remnant tumor cells by beta-particle crossfire effect creating a harsh environment that prevents malignant cell repopulation (Fig. 1).

Hyp is a natural substance found in Hypericum perforatum (St. John's Wort), which has been used as herbal medicine due to its wide range of biological activities $(14,15)$. By means of electrophilic substitution in the activated aromatic ring of Hyp using iodine-123/131 ( $\left.{ }^{123 / 131} \mathrm{I}\right)$ atoms, iodine-123/131-labeled monoiodohypericin $\left({ }^{123 / 131} \mathrm{I}-\mathrm{Hyp}\right)$ can be obtained. Recent studies on targetability and biodistribution of ${ }^{123 / 131} \mathrm{I}-\mathrm{Hyp}$ in well-established animal models have shown its outstanding avidity for necrotic tissues with high-target to non-target ratio over time (16-18). Encouraging therapeutic effects and favorable safety profiles have also been reported in rodents with different tumor engrafts $(16,19)$.

The treatment of solid malignancies generally requires the administration of high radioactive doses for delivering lethal ionizing energy to cancer cells, which however could also irreversibly affect normal organs leading to undesirable side-effects due to radiation overexposure (20). Therefore, for the best efficacy and safety in STR, it is essential to establish the optimal therapeutic range with the tumor dose as high as feasible and the healthy tissue dose as low as possible. To move forward stepwise into clinic, it is mandatory to estimate the absorbed radiation dose in normal organs as well as in tumors after systemic administration of the radiotherapeutic agent ${ }^{131} \mathrm{I}$-Hyp. In this study, the biodistribution of intravenously injected ${ }^{123} \mathrm{I}-\mathrm{Hyp}$ in an animal model of re-perfused partial liver infarction (RPLI) was determined. From biodistribution data of ${ }^{123} \mathrm{I}-\mathrm{Hyp}$, estimation of residence times, absorbed radiation doses per source organ, effective and equivalent doses of ${ }^{131} \mathrm{I}-\mathrm{Hyp}$ in human female and male phantoms was carried out. Finally, the radiation dose of ${ }^{131} \mathrm{I}$-Hyp delivered to tumor was simulated.

\section{Materials and methods}

Tracer preparation. Labeling Hyp, 1,3,4,6,8,13-hexahydroxy10,11-dimethylphenanthro[1,10,9,8-opqra]perylene-7,14-dione (Planta Natural Products, Vienna, Austria; http://www.planta.at/ hyper/hyper.htm), with iodine-123 in the form of sodium iodide (NaI-123; GE Healthcare, Diegem, Belgium) was performed with Iodogen, 1,3,4,6-tetrachloro-3alpha,6alpha-diphenylglycouril (Sigma Chemical Co., St. Louis, MO, USA), as an oxidizing agent in dimethyl sulfoxide (DMSO)/0.05 M sodium phosphate buffer $(90: 10, \mathrm{v} / \mathrm{v})$ at $\mathrm{pH} 7.4$ for $30 \mathrm{~min}$ at room temperature.

Radiochemical yield was determined using a high performance liquid chromatography system (LaChrom Elite, Hitachi L-2130, Tokyo, Japan) connected to a Waters XTerra ${ }^{\circledR} \mathrm{C} 18$ analytical column of $4.6 \mathrm{~mm}$ x $150 \mathrm{~mm}, 5 \mu \mathrm{m}$ (Waters, Milford, MA, USA), a Merck-Hitachi L-4200 HP UV/VIS detector (Tokyo, Japan) at $254 \mathrm{~nm}$ and a Raytest radiometric detector (Raytest, Straubenhardt, Germany). Sample injection 


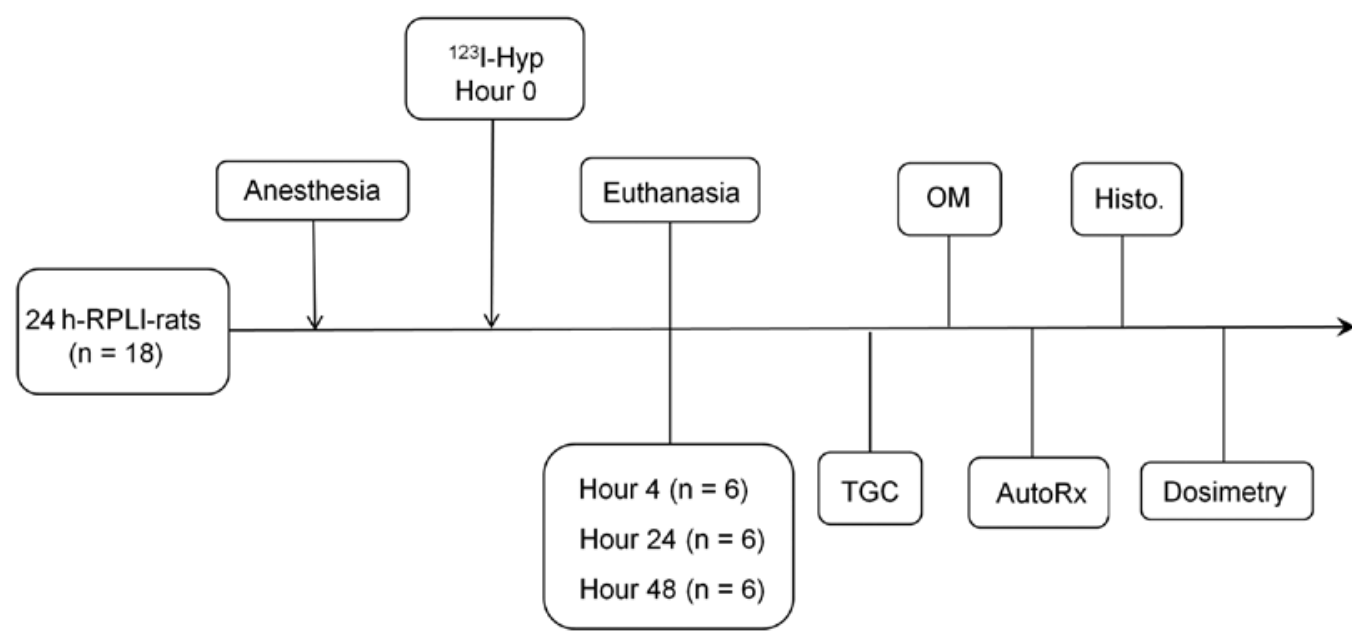

Figure 2. Flow diagram of the experimental procedures. AutoX, autoradiography; Histo, histological analysis; ${ }^{123}$ I-Hyp, iodine-123 labeled hypericin; OM, optical microscopy; RPLI, re-perfused partial liver infarction; TGC, tissue gamma counting.

was carried out via a Rheodyne injector model 7725 valve with a loop of $20 \mu 1$. The mobile phase was a mixture of acetonitrile and $5 \mathrm{mM}$ ammonium acetate buffer of $\mathrm{pH} 7.0$ in a gradient mode at a flow rate of $1.0 \mathrm{ml} / \mathrm{min}$. Purification was performed by using an XTerra C18 semi-preparative column of $10 \mathrm{~mm} \times 250 \mathrm{~mm}, 10 \mu \mathrm{m}$ (Waters) with a loop of $500 \mu 1$ and a flow rate of $3.0 \mathrm{ml} / \mathrm{min}$. Acquisition, integration and evaluation of the output signals were done with GinaStar acquisition software (version 4.4; Raytest). Solvent removal from the purified ${ }^{123} \mathrm{I}$-Hyp fraction was performed by evaporation at $70^{\circ} \mathrm{C}$ under a gentle flush of nitrogen. Reconstitution of the radioactive compound was carried out with a solvent mixture of DMSO/polyethylene glycol 400 (PEG400)/propylene glycol (PG)/water $(25: 25: 25: 25, \mathrm{v} / \mathrm{v} / \mathrm{v} / \mathrm{v})$ containing $\sim 0.007 \times 10^{-3} \mathrm{M}$ hypericin. To control aggregate formation, the resulting formulation was macroscopically examined and then microscopically inspected using the MT-10 illumination system (Olympus, Planegg, Germany). For radioprotection issues, the experiments were performed using the gamma-emitter ${ }^{123} \mathrm{I}$ with a half-life of $13.2 \mathrm{~h}$, as analog of ${ }^{131} \mathrm{I}$.

Animals. The experiment was approved by the local Animal Ethics Committee and was in agreement with the European Ethics Committee guidelines (decree 86/609/EEC). In total, eighteen 10-week-old male Wistar albino rats (Charles River Breeding Laboratories, Chatillon-sur-Chalaronne, France) weighing between 300-350 g were used. Animals were kept in a controlled environment for three days before the study. Animals were given ad libitum access to food (Ssniff Spezialdiäten $\mathrm{GmbH}$, Soest, Germany) and water.

Biodistribution studies. Biodistribution of ${ }^{123} \mathrm{I}-\mathrm{Hyp}$ were studied by tissue gamma counting (TGC). A rat model of re-perfused partial liver infarction (RPLI) was made to induce hepatic necrosis by temporary vascular occlusion (21). The day after, RPLI rats were randomly split into three groups of 6 animals and were anesthetized with intraperitoneal sodium pentobarbital (Nembutal; Sanofi Sante Animale, Brussels, Belgium) at $30 \mathrm{mg} / \mathrm{kg}$. Afterwards, they were given a single intravenous (IV) injection of $12.3 \mathrm{MBq}$ of iodine-123 labeled hypericin $\left({ }^{123} \mathrm{I}-\mathrm{Hyp}\right) /$ hypericin $(0.2 \mathrm{mg} / \mathrm{kg}$ body weight $)$ via a penile vein. Animals were sacrificed by groups at time intervals of 4, 24 and $48 \mathrm{~h}$. The organs (kidneys, spleen, lungs, heart, intestines, stomach, brain and thyroid) and tissues (necrotic and viable liver lobes, muscle, bone and blood) were removed, weighed, and counted for $1 \mathrm{~min}$ (cpm). Samples mounted in a sample changer were measured for radioactivity in a 2480 Automatic Gamma Counter, Wizard2 ${ }^{\text {TM }} 3$ " (Perkin-Elmer, Walthan, MA, USA). The radioactivity uptake in tissues was expressed as percentage of injected dose per organ (\%ID) and percentage of injected dose per gram of tissue (\%ID/g) (Fig. 2).

The biological half-life $\left(\mathrm{Tb}_{1 / 2}\right)$ of ${ }^{123} \mathrm{I}-\mathrm{Hyp} / \mathrm{Hyp}$ was estimated. The activity eliminated via urine and feces was subtracted from the total injected activity during the whole experiment period. After exponential curve fitting of the time-activity plots with high $R$ squared value $\left(R^{2}=1\right), T b_{1 / 2}$ was calculated using the curve equation.

Autoradiography. Specimens of viable liver and hepatic infarction were frozen in isopentane cooled with dry ice for $10 \mathrm{sec}$. The frozen tissues were cut into $10-$ and $50-\mu \mathrm{m}$ thick sections with a cryostat (Shandon Cryotome FSE; Thermo Fisher, Waltham, MA, USA). The slices were thaw-mounted on glass plates $(25 \mathrm{~mm} \times 75 \mathrm{~mm} \times 1 \mathrm{~mm})$ and put in contact with a super resolution screen (Canberra-Packard, Meriden, CT, USA) for $48 \mathrm{~h}$. Digital autoradiographs were generated by reading out imaging plates using a CyClone Phosphor Imager scanner (Canberra-Packard) equipped with OptiQuant ${ }^{\mathrm{TM}}$ software (version 5.0; Canberra-Packard). Autoradiographic analysis was carried out after delineation of regions of interest (ROI) on the necrotic and normal areas. An additional region was set for background subtractions. The activity concentration was expressed in digital light units (DLU) $/ \mathrm{mm}^{2}$ and necrotic to viable tissue (DLU)/mm² ratios were determined (Fig. 2).

Histology. The 10- and 50- $\mu \mathrm{m}$ thick sections of viable liver and hepatic infarction were stained with a conventional hematox- 
ylin and eosin (H\&E) procedure and digitally photographed. The H\&E stained $10-\mu \mathrm{m}$ sections were microscopically observed for evidence of necrosis (Fig. 2).

In vivo stability. In vivo stability of ${ }^{123} \mathrm{I}-\mathrm{Hyp}$ was assessed in the group of RPLI rats having received the radioactive tracer $24 \mathrm{~h}$ earlier. To obtain plasma, $500 \mu \mathrm{l}$ of whole blood was transferred to a VACUETTE ${ }^{\circledR}$ heparin tube and centrifuged at $3,000 \mathrm{rpm}$ for $5 \mathrm{~min}$. For protein precipitation, $200 \mu 1$ of the supernatant plasma was then mixed with $300 \mu$ l of acetonitrile and shaken. After centrifuging the mixture at $3,000 \mathrm{rpm}$ for $5 \mathrm{~min}$, the supernatant was collected and filtered through $0.22-\mu \mathrm{m}$ pore-size filters (GS, Millipore, Bedford, MA, USA). Samples of $200 \mu 1$ were then analyzed by using an HPLC quaternary pump system (LaChrom Elite, Hitachi, Darmstadt, Germany) coupled to an XTerra C18 semi-preparative column, $10 \mathrm{~mm} \times 250 \mathrm{~mm}, 10 \mu \mathrm{m}$ (Waters) and a radiometric detector. Mixtures of acetonitrile and $0.05 \mathrm{M}$ ammonium pH 7.0 in gradient mode $(0 \mathrm{~min}, 5: 95 \mathrm{v} / \mathrm{v} ; 25 \mathrm{~min}, 95: 5 \mathrm{v} / \mathrm{v} ; 30 \mathrm{~min}, 5: 95$ $\mathrm{v} / \mathrm{v}$ ); at a flow rate of $3.0 \mathrm{ml} / \mathrm{min}$ was used as mobile phase. The HPLC eluent was collected in $35 \times 1.0-\mathrm{ml}$ fractions and the radioactivity of the fractions was counted.

\section{Dosimetry calculations}

Dosimetry estimation in hepatic necrosis and normal liver. Mean absorbed radiation doses of ${ }^{131} \mathrm{I}-\mathrm{Hyp}$ in hepatic infarction and normal liver were estimated with the Organ Level Internal Dose Assessment/ Exponential Modeling (OLINDA/EXM ${ }^{\circledR}$ ) application (v1.0; Vanderbilt University, Nashville, TN, USA) (22) using the corresponding percentages of injected dose per gram of ${ }^{123}$ I-Hyp from RPLI rats at 4,24 and $48 \mathrm{~h}$ post-injection combined with a sphere model. The calculations were performed using sphere sizes of $0.01,0.1,0.5,1.0,2.0$ and $4.0 \mathrm{~g}$ considering a self-dose to a spherical organ that contains a uniform distribution of radioactivity (Fig. 2) (23). Although dosimetry in rodents is not representative of human dosimetry, it may provide a preliminary estimation before a new radiopharmaceutical enters clinical trials.

Dosimetry estimation in normal organs. Mean residence times, organ doses per unit of administered activity, effective and equivalent doses of ${ }^{131} \mathrm{I}$-Hyp were estimated using OLINDA/EXM software package and the distribution data of ${ }^{123} \mathrm{I}$-Hyp in normal organs from RPLI rats at 4, 24 and $48 \mathrm{~h}$ post-administration (Fig. 2). For each animal, the percentage of injected dose (\%ID) per organ was extrapolated to an estimated human value using the following equation:

$$
\% I D_{\text {animal }} \times\left(\frac{\text { weight }_{\text {body }}}{\text { weight }_{\text {organ }}}\right)_{\text {animal }} \times\left(\frac{\text { weight }_{\text {organ }}}{\text { weight }_{\text {body }}}\right)_{\text {human }}=\% I D_{\text {human }}
$$

Interspecies allometric scaling was carried out by using the organ weight and body mass of both humans and rats (24). For humans, organ and body weight values of an adult male $(70 \mathrm{~kg})$ and female $(57 \mathrm{~kg})$ standard phantoms were considered (25). For each time point, the averaged \%ID values per organ were obtained for kidneys, liver, spleen and pancreas, lungs, heart, stomach, brain and thyroid. The remainder was calculated as the residual percentage injected dose taking into account the sum of the \%ID of all of the above mentioned organs. The value of \%ID for each time point was also adjusted for the different physical half-life of ${ }^{131}$. The residence time was determined as the area under curve (AUC) of the corresponding time-activity curve (TAC) by a mono-exponential fit through the three data points. For thyroid, no acceptable fitting was possible and the AUC was estimated by applying the trapezoid rule and assuming only physical decay after the last data point. In excretory organs (intestines, urinary bladder), the fractional injected activity excreted through both pathways was estimated by extrapolating the accumulated or excreted activity at the different time points to an excreted total fraction of $100 \%$. The fraction that is excreted through the gastro-intestinal track was used to estimate the residence times for the small intestine, upper and lower large intestines using the ICRP gastro-intestinal model (26). The fraction cleared through the urine together with the clearing half-life was used as input for the voiding bladder model to estimate the residence time for the urinary bladder taking into account a voiding bladder interval of $4 \mathrm{~h}$. Absorbed radiation doses were then calculated from the residence times in all source organs (Fig. 2).

Statistical analysis. Data are expressed as mean \pm standard deviation (SD). Statistical analysis was performed using a paired t-test by the computer software GraphPad Prism version 5.00 for Windows (GraphPad Software, San Diego, CA, USA, www.graphpad.com). Values of $\mathrm{P}<0.05$ were considered to indicate a statistically significant difference.

\section{Results}

Tracer preparation. The radiochemical yield of ${ }^{123} \mathrm{I}$-Hyp was greater than $95 \%$ with a specific activity around $1.0 \mathrm{GBq} / \mu \mathrm{mol}$ achieved. After purification, the resulting ${ }^{123} \mathrm{I}-\mathrm{Hyp}$ with a radiochemical purity of $99 \%$ was formulated at a concentration of $37 \mathrm{MBq} / \mathrm{ml}$ in DMSO/PEG400/PG/water (25:25:25:25, $\mathrm{v} / \mathrm{v} / \mathrm{v} / \mathrm{v})$ and $0.25 \mathrm{mg} / \mathrm{kg}$ of unlabeled Hyp. No aggregates or particulates were detected in the final solution by visual inspection, but minimum aggregate formation was observed microscopically.

Animal studies. The rat model of RPLI was successfully established. All rats survived the anesthesia and temporary vascular occlusion during surgery. This model was preferred owing to the high reproducibility and low mortality rate of the animals during the preparation (21).

Biodistribution studies. The organ and tissue distribution of the intravenously administered ${ }^{123} \mathrm{I}-\mathrm{Hyp} / \mathrm{Hyp}$ in rats with RPLI was studied at 4, 24 and $48 \mathrm{~h}$ p.i and the results are summarized in Table I.

Tissue distribution in normal organs. By TGC, maximum levels of radioactivity were found in blood at $4 \mathrm{~h}$, reaching values of $25.62 \pm 1.69 \% \mathrm{ID}$, which dropped to $3.18 \pm 0.60 \% \mathrm{ID}$ at $24 \mathrm{~h}$. In most normal organs, peaks of uptake were detected at $4 \mathrm{~h} \mathrm{p.i,} \mathrm{which} \mathrm{progressively} \mathrm{declined} \mathrm{due} \mathrm{to} \mathrm{the}{ }^{123} \mathrm{I}-\mathrm{Hyp} / \mathrm{Hyp}$ clearance from the blood compartment over time. The organs showing the highest percentage of injected dose (\%ID) were the liver $(14.23 \pm 1.61)$ followed by spleen $(4.96 \pm 0.83)$ and lungs $(3.33 \pm 0.22)$. These values rapidly decreased by more than $65 \%$ within $24 \mathrm{~h}$ in spleen and liver. On the contrary, lungs 
Table I. Tissue distribution of ${ }^{131} \mathrm{I}-\mathrm{Hyp} / \mathrm{Hyp}$ in rats with RPLI (n=6/group).

\begin{tabular}{|c|c|c|c|c|c|c|}
\hline \multirow[b]{2}{*}{ Samples } & \multicolumn{2}{|c|}{$4 \mathrm{~h}$} & \multicolumn{2}{|c|}{$24 \mathrm{~h}$} & \multicolumn{2}{|c|}{$48 \mathrm{~h}$} \\
\hline & $\% \mathrm{ID} \pm \mathrm{SD}$ & $\% \mathrm{ID} / \mathrm{g} \pm \mathrm{SD}$ & $\% \mathrm{ID} \pm \mathrm{SD}$ & $\% \mathrm{ID} / \mathrm{g} \pm \mathrm{SD}$ & $\% \mathrm{ID} \pm \mathrm{SD}$ & $\% \mathrm{ID} / \mathrm{g} \pm \mathrm{SD}$ \\
\hline Blood & $25.62 \pm 1.69$ & $1.39 \pm 0.22$ & $3.18 \pm 0.60$ & $0.17 \pm 0.06$ & $2.28 \pm 0.44$ & $0.12 \pm 0.03$ \\
\hline Brain & $0.09 \pm 0.03$ & $0.06 \pm 0.01$ & $0.01 \pm 0.002$ & $0.01 \pm 0.001$ & $0.01 \pm 0.001$ & $0.01 \pm 0.001$ \\
\hline Thyroid & $0.15 \pm 0.03$ & $0.33 \pm 0.06$ & $0.49 \pm 0.13$ & $2.78 \pm 0.54$ & $0.84 \pm 0.24$ & $4.48 \pm 0.73$ \\
\hline Lungs & $3.33 \pm 0.22$ & $2.57 \pm 0.32$ & $2.13 \pm 0.54$ & $1.81 \pm 0.12$ & $2.17 \pm 0.26$ & $2.52 \pm 0.08$ \\
\hline Heart & $0.83 \pm 0.09$ & $0.91 \pm 0.29$ & $0.41 \pm 0.14$ & $0.91 \pm 0.09$ & $0.39 \pm 0.03$ & $0.41 \pm 0.08$ \\
\hline Liver & $14.23 \pm 1.61$ & $1.57 \pm 0.29$ & $1.50 \pm 0.36$ & $0.16 \pm 0.04$ & $1.74 \pm 0.22$ & $0.22 \pm 0.06$ \\
\hline NL & $9.15 \pm 2.83$ & $3.94 \pm 1.60$ & $11.64 \pm 0.48$ & $6.97 \pm 0.88$ & $14.52 \pm 1.47$ & $10.99 \pm 1.12$ \\
\hline Pancreas & $0.23 \pm 0.08$ & $0.43 \pm 0.10$ & $0.30 \pm 0.11$ & $0.39 \pm 0.08$ & $0.25 \pm 0.02$ & $0.30 \pm 0.05$ \\
\hline Spleen & $4.96 \pm 0.83$ & $4.08 \pm 1.01$ & $0.72 \pm 0.07$ & $0.58 \pm 0.07$ & $0.61 \pm 0.10$ & $0.45 \pm 0.08$ \\
\hline Stomach & $2.73 \pm 0.30$ & $0.95 \pm 0.26$ & $1.18 \pm 0.32$ & $0.27 \pm 0.07$ & $0.99 \pm 0.17$ & $0.34 \pm 0.05$ \\
\hline Intestines & $12.23 \pm 3.42$ & $0.59 \pm 0.05$ & $14.57 \pm 2.83$ & $0.75 \pm 0.05$ & $6.29 \pm 0.53$ & $0.35 \pm 0.07$ \\
\hline Kidneys & $2.18 \pm 0.26$ & $0.92 \pm 0.20$ & $0.96 \pm 0.25$ & $0.39 \pm 0.04$ & $0.83 \pm 0.09$ & $0.31 \pm 0.05$ \\
\hline Muscle & $18.16 \pm 2.42$ & $0.16 \pm 0.06$ & $12.17 \pm 4.28$ & $0.12 \pm 0.04$ & $16.34 \pm 0.76$ & $0.17 \pm 0.003$ \\
\hline Bone & $22.23 \pm 2.14$ & $0.83 \pm 0.27$ & $4.23 \pm 2.14$ & $0.21 \pm 0.04$ & $2.55 \pm 0.96$ & $0.01 \pm 0.002$ \\
\hline Feces $(\mathrm{CD})$ & - & - & $38.08 \pm 1.89$ & - & $45.03 \pm 0.75$ & - \\
\hline Urine (CD) & - & - & $3.69 \pm 1.02$ & - & $8.33 \pm 0.96$ & - \\
\hline $\mathrm{NL} / \mathrm{L}$ & & $2.17 \pm 0.29$ & & $42.85 \pm 4.61$ & & $53.69 \pm 5.19$ \\
\hline P-value (NL vs. L) & & $>0.05$ & & $<0.05$ & & $<0.05$ \\
\hline
\end{tabular}

Values are shown as mean \pm standard deviation $(\mathrm{SD})$. Differences between tissues are considered significant at $\mathrm{P}<0.05$. $\mathrm{L}$, liver; $\mathrm{CD}$, cumulative dose; NL, necrotic liver; \%ID, percentage of injected dose; $\% \mathrm{ID} / \mathrm{g}$, percentage of injected dose per gram of tissue.

showed the slowest clearance rate accumulating $2.13 \pm 0.54 \%$ and $2.17 \pm 0.26 \%$ ID at 24 and $48 \mathrm{~h}$, respectively. Among all organs examined, brain showed the lowest ${ }^{123} \mathrm{I}$-Hyp uptake $(<0.1 \%$ ID) .

In terms of radioactivity concentrations $(\% \mathrm{ID} / \mathrm{g})$, the spleen exhibited the highest value $(4.08 \pm 1.01 \%)$ at $4 \mathrm{~h}$. Lungs, liver and stomach also showed relatively pronounced accumulation compared to other normal organs. In thyroid, low uptake $(0.33 \pm 0.06 \% \mathrm{ID} / \mathrm{g})$ were observed at $4 \mathrm{~h}$, followed by an increase at $24 \mathrm{~h}(2.78 \pm 0.54 \% \mathrm{ID} / \mathrm{g})$ and $48 \mathrm{~h}(4.48 \pm 0.73 \% \mathrm{ID} / \mathrm{g})$. During the first few days after tracer injection, a rise in levels of radioactivity in urine was also found. Bone and muscle showed total uptake of $22.23 \pm 2.14$ and $18.16 \pm 2.42 \%$ ID, whereas the radioactivity concentration only accounted for $0.83 \pm 0.27$ and $0.16 \pm 0.06 \% \mathrm{ID} / \mathrm{g}$ due to their large masses, respectively.

At $24 \mathrm{~h}$, lungs, liver and stomach showed the greatest percentages of injected dose (\%ID). Except for lungs and thyroid, all other organs exhibited values lower than $1.0 \%$ of radioactivity concentration. Similar results were found at $48 \mathrm{~h}$ after ${ }^{123} \mathrm{I}$-Hyp/Hyp administration.

As shown in Fig. 3A, in all examined time points, extensive levels of radioactivity were detected in intestines (14.57 $\pm 2.83 \% \mathrm{ID}$ at $24 \mathrm{~h}$ and $6.29 \pm 0.53 \% \mathrm{ID}$ at $48 \mathrm{~h}$ ) and feces $(38.08 \pm 1.89 \%$ ID at $24 \mathrm{~h}$ and $45.03 \pm 0.75 \%$ ID at $48 \mathrm{~h})$. Moderate amounts of radioactivity were secreted via urine $(3.69 \pm 1.02 \%$ ID at $24 \mathrm{~h}$ and $8.33 \pm 0.96 \%$ ID at $48 \mathrm{~h})$ within $48 \mathrm{~h}$. In kidneys, however, relative low percentages of injected doses were observed at $4 \mathrm{~h}(2.18 \pm 0.26 \%$ ID), this value decreased to
$0.96 \pm 0.25 \%$ ID at $24 \mathrm{~h}$ after ${ }^{123} \mathrm{I}-\mathrm{Hyp} / \mathrm{Hyp}$ administration. The $\mathrm{Tb}_{1 / 2}$ for ${ }^{123} \mathrm{I}-\mathrm{Hyp} / \mathrm{Hyp}$ accounted for approximately $40.8 \mathrm{~h}$ as shown in Fig. 3B.

Radioactivity accumulation patterns in necrotic and normal liver tissues. With TGC, hepatic infarction rapidly retained high radioactivity levels up to $3.94 \pm 1.60,6.97 \pm 0.88$ and $10.99 \pm 1.12 \% \mathrm{ID} / \mathrm{g}$ at 4,24 and $48 \mathrm{~h}$, respectively. A rapid decline in ${ }^{123} \mathrm{I}-\mathrm{Hyp} / \mathrm{Hyp}$ accumulation was found, instead, in viable liver accounting for $1.57 \pm 0.29$ and $0.16 \pm 0.04 \% \mathrm{ID} / \mathrm{g}$ at 4 and $24 \mathrm{~h}$, respectively. Hence, increasing values of radioactivity uptake ratios between the hepatic infarction and the viable liver were achieved over time from $2.17 \pm 0.29$ at $4 \mathrm{~h}$ to $53.69 \pm 5.19$ at $48 \mathrm{~h}$, as confirmed by autoradiography (Table I).

Fig. 4 shows typical autoradiographs of $50-\mu \mathrm{m}$ fresh thick sections in comparison to the corresponding H\&E-stained liver specimens collected from RPLI rats at 4, 24 and $48 \mathrm{~h}$ after ${ }^{123} \mathrm{I}-\mathrm{Hyp} / \mathrm{Hyp}$ administration. Histological outlook fully matched those of autoradiography confirming the selective accumulation of ${ }^{123} \mathrm{I}-\mathrm{Hyp} / \mathrm{Hyp}$ in hepatic infarction and the lack of tracer retention in viable liver, as proven by microscopic views of the respective H\&E-stained $10-\mu \mathrm{m}$ sections.

In vivo stability. Metabolite analysis by HPLC in plasma from RPLI rats $24 \mathrm{~h}$ after ${ }^{123} \mathrm{I}-\mathrm{Hyp}$ administration is shown in Fig. 5. Two peaks corresponding to free iodide and intact ${ }^{123} \mathrm{I}-\mathrm{Hyp}$ was observed with retention time of $2.45 \pm 0.18$ and $22.57 \pm 0.34 \mathrm{~min}$, respectively. No significant dehalogenation was seen with levels of circulating iodine in blood of $5.0 \pm 1.8 \%$. 

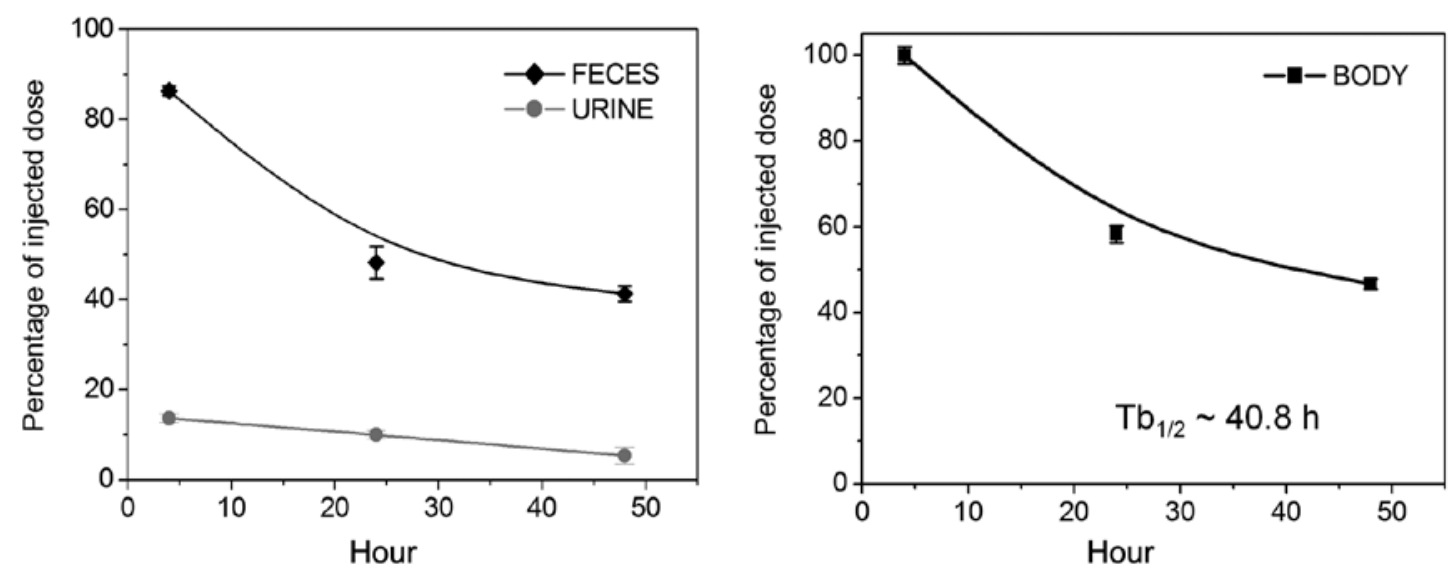

Figure 3. Elimination route of ${ }^{123 / 131} \mathrm{I}-\mathrm{Hyp} / \mathrm{Hyp}$ in RPLI rats. (A) Excretion pattern distinguished by a predominant hepatobiliary and intestinal elimination in contrast with a minimum renal clearance. (B) The total-body clearance of ${ }^{123} \mathrm{I}-\mathrm{Hyp} / \mathrm{Hyp}$ follows a mono-exponential kinetic exhibiting a biological half-life (Tb1/2) of $40.8 \mathrm{~h}$.

Hepatic Infarction
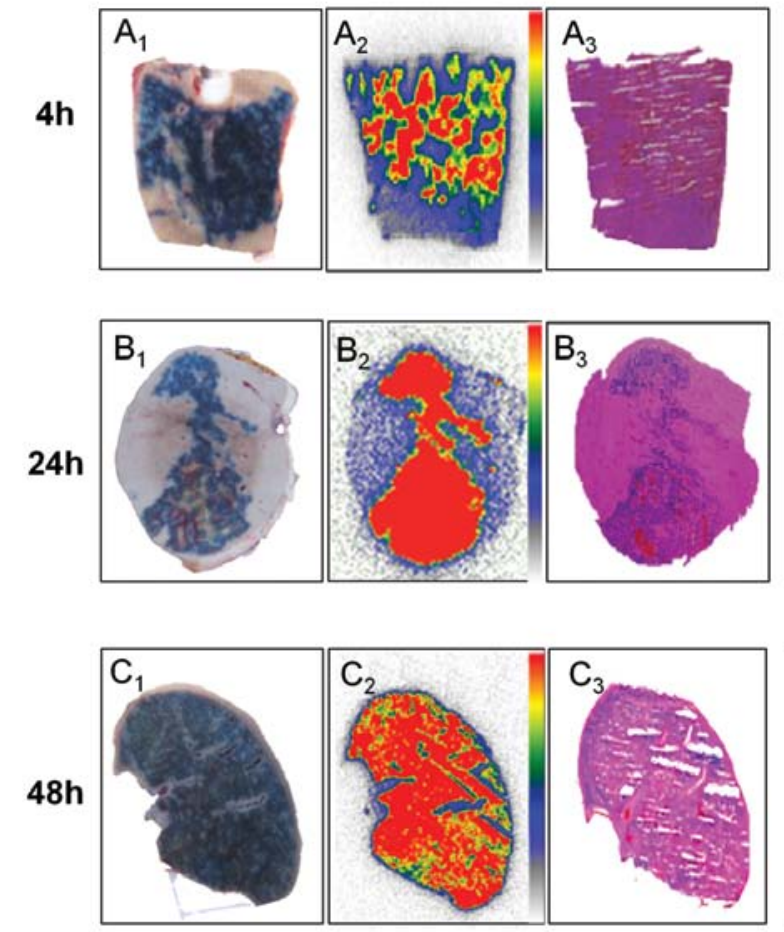

Normal Liver
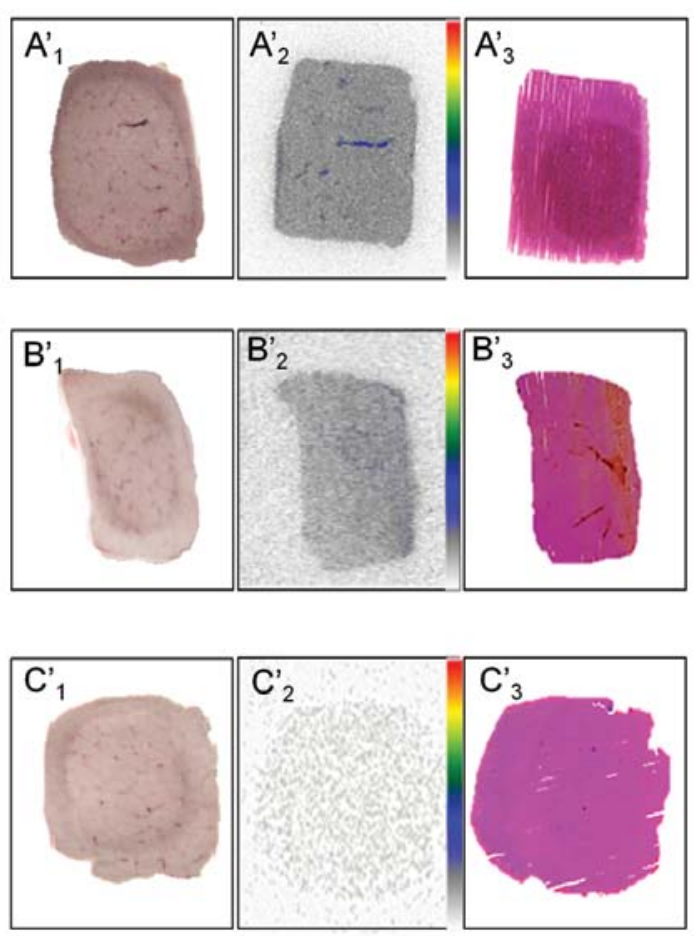

Figure 4. Postmortem analysis of necrotic and viable liver from RPLI rats receiving ${ }^{123}$ I-Hyp/Hyp followed by the necrosis-avid dye Evans blue. At 4 , 24 and $48 \mathrm{~h}$ after radioactivity injection, liver necrosis is outlined by the Evans blue as a blue region (A1, B1, C1), with viable liver without staining (A1', B1', C1'). Autoradiograms of 50- $\mu$ m-thick sections show higher tracer accumulation in hepatic infarction (A2, B2, C2) than in viable liver (A2', B2', C2'). The color code bar represents the coding scheme for the radioactivity. On histology sections, the presence of scattered liver necrosis (A3, B3, C3) and the location of the normal liver (A3', B3', C3') are confirmed.

\section{Dosimetry}

Dosimetry estimation in hepatic infarction versus normal liver. Mean absorbed doses of ${ }^{131}$ I-Hyp by hepatic infarction and normal liver in RPLI rats calculated with OLINDA/EXM are shown in Table II. Hepatic infarction received significantly higher doses $(276-93,600 \mathrm{mGy} / \mathrm{MBq})$ compared to that in normal liver $(4.2 \mathrm{mGy} / \mathrm{MBq}),(\mathrm{P}<0.05)$. Dosimetric calculations based on the sphere model showed high absorbed doses for all the different radii of tumors studied, especially those with the smallest size $(0.01 \mathrm{~g})$.
Residence time and absorbed dose calculations. Percentage of injected dose of ${ }^{123} \mathrm{I}$-Hyp in different organs and tissues of adult female $(57 \mathrm{~kg})$ and male $(70 \mathrm{~kg})$ humans were estimated from biodistribution of RPLI rats and the results are summarized in Table III. Overall, no statistically significant gender difference in organ radiation doses was found in terms of radioactivity accumulation $(\mathrm{P}>0.05)$. At the $4 \mathrm{~h}$ period, the highest ${ }^{123}$ I-Hyp uptake was detected in the liver followed by lungs, spleen and intestines. In contrast, thyroid, brain and stomach showed the lowest levels $(<1.0 \%)$ of radioactivity. At 


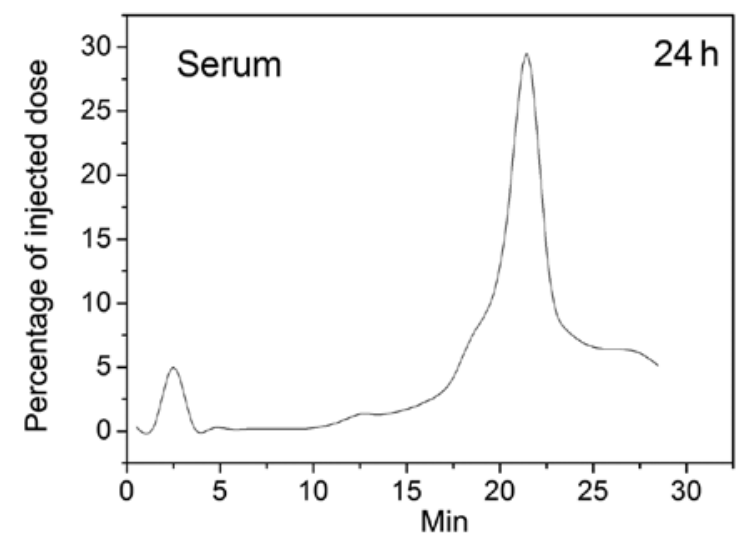

Figure 5. Typical HPLC radio-chromatograms of ${ }^{123} \mathrm{I}-\mathrm{Hyp}$ in serum at $24 \mathrm{~h}$ after administration. Two peaks were seen at 2.45 and 22.57 min corresponding to free iodide and ${ }^{123} \mathrm{I}$-Hyp. Relatively low percentages of free iodide were observed.

24 and $48 \mathrm{~h}$ after radioactivity injection, the uptake level was relatively low $(<1.0 \%)$ in most organs, except in lungs, intestines and liver.

Table IV shows the mean residence times, organ absorbed doses per unit activity administered and the equivalent and effective doses for ${ }^{131} \mathrm{I}-\mathrm{Hyp}$ in a reference adult female phantom. The whole-body remainder showed the longest residence time $(7.65 \mathrm{E} 001 \mathrm{MBq} \cdot \mathrm{h} / \mathrm{MBq})$, followed by lungs (6.82E000 $\mathrm{MBq} \bullet \mathrm{h} / \mathrm{MBq}$ ), lower large intestine (LLI) wall (1.80E001 MBq॰h/MBq), upper large intestine (ULI) wall $(1.06 \mathrm{E} 001 \mathrm{MBq} \bullet \mathrm{h} / \mathrm{MBq})$ and thyroid (1.44E000 MBq•h/MBq). The shortest residence times were found in brain $(5.17 \mathrm{E}-02$ $\mathrm{MBq} \bullet \mathrm{h} / \mathrm{MBq})$, pancreas (1.85E-01 MBq॰h/MBq), stomach wall $(1.71 \mathrm{E}-01 \mathrm{MBq} \bullet \mathrm{h} / \mathrm{MBq})$ and kidneys (3.93E-01 MBq॰h/MBq). Regarding the absorbed radiation doses, the highest mean values were detected in thyroids (1.01E001 mGy/MBq), LLI walls $(8.57 \mathrm{E} 000 \mathrm{mGy} / \mathrm{MBq})$, ULI walls (3.62E000 mGy/MBq) and lungs (1.16E000 mGy/MBq). In contrast, the tissues having lowest absorbed radiation doses $(<1.0 \mathrm{mGy} / \mathrm{MBq})$ were the brain followed by pancreas, spleen, skin, testes and red marrow.
Table II. Dosimetry of ${ }^{131} \mathrm{I}-\mathrm{Hyp} / \mathrm{Hyp}$ in hepatic infarction from rats with re-perfused liver infarction.

\begin{tabular}{lc} 
Sphere mass $(\mathrm{g})$ & Dose $(\mathrm{mGy} / \mathrm{MBq})$ \\
\hline 0.01 & $9.36 \mathrm{E}+04$ \\
0.1 & $1.01 \mathrm{E}+04$ \\
0.5 & $2.07 \mathrm{E}+03$ \\
1.0 & $1.08 \mathrm{E}+03$ \\
2.0 & $5.43 \mathrm{E}+02$ \\
4.0 & $2.76 \mathrm{E}+02$
\end{tabular}

The mean effective dose and the effective dose equivalent were, respectively, 2.00E000 and 1.59E000 mSv/MBq.

The mean residence times, organ absorbed doses per unit radioactivity administered and the equivalent and effective doses for ${ }^{131} \mathrm{I}$-Hyp in a reference adult male phantom $(70 \mathrm{~kg})$ are shown in Table V. Similar to the female human phantoms, the whole-body remainder exhibited the longest residence time accounting for 7.59E001 MBq•h/MBq. Among organs, LLI wall $(1.80 \mathrm{E} 001 \mathrm{MBq} \bullet \mathrm{h} / \mathrm{MBq})$, ULI wall (1.06E001 $\mathrm{MBq} \cdot \mathrm{h} / \mathrm{MBq})$, lungs $(6.58 \mathrm{E} 000 \mathrm{MBq} \cdot \mathrm{h} / \mathrm{MBq})$, small intestine (3.40E000 MBq•h/MBq), liver (1.55E000 MBq•h/MBq) and thyroid (1.36E000 MBq•h/MBq) showed relatively longer residence times. The organs with the shortest residence time were the brain (4.71E-02 MBq•h/MBq), stomach wall (1.49E-01 $\mathrm{MBq} \cdot \mathrm{h} / \mathrm{MBq}$ ) and pancreas (1.58E-01 MBq $\bullet / \mathrm{MBq})$. The highest radiation doses were found in thyroids $(1.01 \mathrm{E} 001 \mathrm{mGy} /$ $\mathrm{MBq}$ ) followed by the bowel structures including lower large intestine (LLI) (5.66E000 mGy/MBq) and ULI (2.26E000 $\mathrm{mGy} / \mathrm{MBq}$ ) walls. Lower doses were observed, however, in important therapy limiting normal tissues such as kidneys and red bone marrow with values of $2.27 \mathrm{E}-01 \mathrm{mGy} / \mathrm{MBq}$ and 1.47E-01 mGy/MBq. The mean effective dose and the effective dose equivalent were estimated to be 1.31E000 and 1.01E000 $\mathrm{mSv} / \mathrm{MBq}$, respectively. Overall, organ absorbed doses per unit

Table III. Percentage of injected dose (\%ID) of ${ }^{123} \mathrm{I}-\mathrm{Hyp} / \mathrm{Hyp}$ in human organs estimated from the biodistribution in RPLI rats (n=6/group).

$4 \mathrm{~h}$

Female Male

\section{Brain}

Thyroid

Lungs

$0.35 \pm 0.08$

Heart

$0.03 \pm 0.01$

Liver

$9.66 \pm 1.47$

Spleen

$1.00 \pm 0.23$

Stomach

$10.22 \pm 1.20$

Intestines

$4.72 \pm 1.38$

Intestines

$0.62 \pm 0.15$

$2.70 \pm 0.51$

$1.18 \pm 0.27$

$0.32 \pm 0.07$
$0.03 \pm 0.01$
$9.32 \pm 1.42$
$1.02 \pm 0.23$
$10.77 \pm 1.26$
$4.45 \pm 1.30$
$0.54 \pm 0.13$
$2.31 \pm 0.44$
$0.99 \pm 0.22$

$0.04 \pm 0.01$

$0.23 \pm 0.08$

$7.02 \pm 1.19$

$0.49 \pm 0.13$

$1.10 \pm 0.28$

$0.43 \pm 0.12$

$0.18 \pm 0.04$

$3.48 \pm 0.51$

$0.51 \pm 0.09$
$\% \mathrm{ID} \pm \mathrm{SD}$

$24 \mathrm{~h}$

$48 \mathrm{~h}$ 
Table IV. Dosimetry estimations of ${ }^{131} \mathrm{I}-\mathrm{Hyp} / \mathrm{Hyp}$ by OLINDA/EXM software in a 57-kg female adult phantom.

\begin{tabular}{|c|c|c|}
\hline Organ & $\begin{array}{l}\text { Residence time } \\
(\mathrm{MBq} \cdot \mathrm{h} / \mathrm{MBq})\end{array}$ & $\begin{array}{l}\text { Organ doses } \\
(\mathrm{mGy} / \mathrm{MBq})\end{array}$ \\
\hline Adrenals & $0.00 \mathrm{E} 000$ & 3.34E-01 \\
\hline Brain & $5.17 \mathrm{E}-02$ & $5.22 \mathrm{E}-02$ \\
\hline Breasts & $0.00 \mathrm{E} 000$ & $2.50 \mathrm{E}-01$ \\
\hline Gallbladder & - & 4.22E-01 \\
\hline LLI wall & $1.80 \mathrm{E} 001$ & 8.57E000 \\
\hline Small intestine & $3.40 \mathrm{E} 000$ & $1.15 \mathrm{E} 000$ \\
\hline Stomach wall & $1.71 \mathrm{E}-01$ & $4.08 \mathrm{E}-01$ \\
\hline ULI wall & $1.06 \mathrm{E} 001$ & 3.62E000 \\
\hline Heart wall & 4.36E-01 & $3.84 \mathrm{E}-01$ \\
\hline Kidneys & 3.93E-01 & $3.46 \mathrm{E}-01$ \\
\hline Liver & $1.47 \mathrm{E} 000$ & $2.86 \mathrm{E}-01$ \\
\hline Lungs & $6.82 \mathrm{E} 000$ & $1.16 \mathrm{E} 000$ \\
\hline Muscle & $0.00 \mathrm{E} 000$ & $3.10 \mathrm{E}-01$ \\
\hline Ovaries & $0.00 \mathrm{E} 000$ & 7.39E-01 \\
\hline Pancreas & $1.85 \mathrm{E}-01$ & $4.58 \mathrm{E}-01$ \\
\hline Red marrow & $0.00 \mathrm{E} 000$ & $3.03 \mathrm{E}-01$ \\
\hline Osteogenic cells & - & $5.94 \mathrm{E}-01$ \\
\hline Skin & - & $2.36 \mathrm{E}-01$ \\
\hline Spleen & $6.31 \mathrm{E}-01$ & $6.88 \mathrm{E}-01$ \\
\hline Testes & $0.00 \mathrm{E} 000$ & - \\
\hline Thymus & $0.00 \mathrm{E} 000$ & $2.98 \mathrm{E}-01$ \\
\hline Thyroid & $1.44 \mathrm{E} 000$ & $1.01 \mathrm{E} 001$ \\
\hline Urinary bladder wall & - & 4.69E-01 \\
\hline Urinary bladder contents & $2.16 \mathrm{E}-01$ & - \\
\hline Uterus & $0.00 \mathrm{E} 000$ & 4.91E-01 \\
\hline Total body & - & $3.72 \mathrm{E}-01$ \\
\hline Remainder & 7.65E001 & - \\
\hline Effective dose equivalent & - & $1.59 \mathrm{E} 000$ \\
\hline Effective dose & - & $2.00 \mathrm{E} 000$ \\
\hline
\end{tabular}

LLI lower large intestine; ULI upper large intestine.

activity administered and the equivalent and effective doses seemed to be higher in human female than in male.

\section{Discussion}

A good therapeutic radiopharmaceutical must deliver radiation doses high enough to destroy cancer cells while keeping the dose at a minimum to healthy tissues. Therefore, for the implementation of any of such therapeutics, it is essential to predict tumor response, to estimate the normal organ doses and to identify the dose limiting organs for guaranteeing the delivered doses within a safe range. In this study, we estimated the dosimetry of the potential radiotherapeutic agent ${ }^{131} \mathrm{I}-\mathrm{Hyp}$ in tumor and normal human organs. For radioprotection, since ${ }^{123}$ I-Hyp shares similar biological profiles with ${ }^{131}$ I-Hyp (19), dosimetry calculations were performed following the animal
Table V. Dosimetry estimations of ${ }^{131} \mathrm{I}-\mathrm{Hyp} / \mathrm{Hyp}$ by OLINDA/EXM software in a 70-kg male adult phantom.

\begin{tabular}{|c|c|c|}
\hline Organ & $\begin{array}{l}\text { Residence time } \\
(\mathrm{MBq} \bullet \mathrm{h} / \mathrm{MBq})\end{array}$ & $\begin{array}{l}\text { Organ doses } \\
(\mathrm{mGy} / \mathrm{MBq})\end{array}$ \\
\hline Adrenals & $0.00 \mathrm{E} 000$ & $2.58 \mathrm{E}-01$ \\
\hline Brain & $4.71 \mathrm{E}-02$ & $4.06 \mathrm{E}-02$ \\
\hline Breasts & $0.00 \mathrm{E} 000$ & $1.95 \mathrm{E}-01$ \\
\hline Gallbladder & - & 3.34E-01 \\
\hline LLI wall & $1.80 \mathrm{E} 001$ & 7.95E000 \\
\hline Small intestine & $3.40 \mathrm{E} 000$ & $9.75 \mathrm{E}-01$ \\
\hline Stomach wall & $1.49 \mathrm{E}-01$ & 3.19E-01 \\
\hline ULI wall & $1.06 \mathrm{E} 001$ & $3.20 \mathrm{E} 000$ \\
\hline Heart wall & $4.42 \mathrm{E}-01$ & $2.97 \mathrm{E}-01$ \\
\hline Kidneys & $3.30 \mathrm{E}-01$ & $2.74 \mathrm{E}-01$ \\
\hline Liver & $1.55 \mathrm{E} 000$ & $2.22 \mathrm{E}-01$ \\
\hline Lungs & $6.58 \mathrm{E} 000$ & $8.88 \mathrm{E}-01$ \\
\hline Muscle & $0.00 \mathrm{E} 000$ & $2.45 \mathrm{E}-01$ \\
\hline Ovaries & $0.00 \mathrm{E} 000$ & $5.68 \mathrm{E}-01$ \\
\hline Pancreas & $1.58 \mathrm{E}-01$ & $3.56 \mathrm{E}-01$ \\
\hline Red marrow & $0.00 \mathrm{E} 000$ & $2.47 \mathrm{E}-01$ \\
\hline Osteogenic cells & - & $4.48 \mathrm{E}-01$ \\
\hline Skin & - & $1.85 \mathrm{E}-01$ \\
\hline Spleen & 5.94E-01 & 5.37E-01 \\
\hline Testes & $0.00 \mathrm{E} 000$ & 2.34E-01 \\
\hline Thymus & $0.00 \mathrm{E} 000$ & $2.31 \mathrm{E}-01$ \\
\hline Thyroid & $1.36 \mathrm{E} 000$ & 7.89E000 \\
\hline Urinary bladder wall & - & 3.92E-01 \\
\hline Urinary bladder contents & $2.16 \mathrm{E}-01$ & - \\
\hline Uterus & $0.00 \mathrm{E} 000$ & 3.92E-01 \\
\hline Total body & - & 2.93E-01 \\
\hline Remainder & 7.59E001 & - \\
\hline Effective dose equivalent & - & $1.34 \mathrm{E} 000$ \\
\hline Effective dose & - & $1.72 \mathrm{E} 000$ \\
\hline
\end{tabular}

LLI lower large intestine; ULI upper large intestine.

biodistribution of Hyp labeled with the gamma-emitter ${ }^{123} \mathrm{I}$. This radioisotope has been widely used for diagnostic imaging, dosimetry and therapy planning of ${ }^{131}$ I-labeled agents $(27,28)$.

In conventional SRT, cancer cells receive the 'self-dose' from the radionuclides taken up by themselves as well as the 'cross-dose' of radiation emitted from adjacent cells and tissues (crossfire effect). In the OncoCiDia approach, on the other hand, the eradication of cancer cells mainly depends on the cross-dose of radiation from ${ }^{131} \mathrm{I}$-Hyp accumulated in the nearby necrotic sites after a VDA attack. It raises a critical concern whether the total dose that could be delivered by OncoCiDia is enough or not to effectively kill those targeted cancer cells. Some favorable arguments include: i) radioiodinated Hyp can selectively and intensively be distributed in necrosis at concentrations as high as $4-10 \% \mathrm{ID} / \mathrm{g}(19,29)$; ii) radioiodinated Hyp presents a biological half-life $\left(\mathrm{Tb}_{1 / 2}\right)$ of 
two days allowing high levels of accumulation in the tumor site before being eliminated from the body; and iii) the relatively long physical half-life of 8.06 days with beta-emitting ${ }^{131} \mathrm{I}$ fits well with the prolonged retention of ${ }^{131} \mathrm{I}-\mathrm{Hyp}$ at intratumoral necrosis, which may synergistically create a hostile microenvironment sterilizing the residual cancer cells $(16,19,29,30)$.

Indeed, the current study has demonstrated that ${ }^{131} \mathrm{I}-\mathrm{Hyp}$ consequently delivered the radiation doses as high as 276-93,600 $\mathrm{mGy} / \mathrm{MBq}$ to necrotic tissues, and such emitted beta particles with a maximum energy of $606 \mathrm{keV}$ can penetrate through the tissue up to a distance of 0.6-2.0 $\mathrm{mm}$ from the resident site (31). Eventually, the nearby cancer cells may be reached, irradiated and killed by the beta radiation associated tumoricidal effect via DNA damage and apoptotic activation (32). This well explains the observed tumor shrinkage and growth delay as reported in animals bearing different engrafted tumors after being treated with a single episode of OncoCiDia $(16,19)$.

With the exception in thyroid cancers after thyroidectomy to ablate residual tumor tissues where the doses as high as 25,000 Gy could be delivered after administering 3.7-7.4 GBq of $\mathrm{Na}^{131}$ I to the patient (33), we believe that the dose deposited in tumors after administration of ${ }^{131} \mathrm{I}$-Hyp could be higher than that estimated for other radiotherapeutic agents currently under preclinical and clinical stages. For instance, in a preclinical study of ${ }^{131}$ I-chimeric(ch) TNT-1/B monoclonal antibody recognizing the histone fraction $\mathrm{H} 1$ in necrotic tissues from ME-180 human cervical tumors in nude mice, the absorbed tumor dose ranged between 366-3,610 $\mathrm{mGy} / \mathrm{MBq}$ (34). Biodistribution and dosimetry estimations for ${ }^{177}$ Lu-DOTA-conjugated AE105 peptide that targets urokinase-type plasminogen activator receptor (UPAR) in human colorectal cancer xenografts only delivered a radiation dose of $5.8 \mathrm{mGy} / \mathrm{MBq}$ to the tumor (35). In preclinical evaluation of the conjugate ${ }^{177} \mathrm{Lu}$-pertuzumab for treating breast tumors overexpressing HER-2 tyrosine kinase receptor, the radiation doses deposited in cancer cells was $6,900 \mathrm{mGy} / \mathrm{MBq}$ (36). In a study on ${ }^{131} \mathrm{I}$-MIBG dosimetry using ${ }^{124} \mathrm{I}-\mathrm{MIBG}$ PET/CT conducted with a murine xenograft model of neuroblastoma having received radioactive doses in the range of 52.8-206 MBq, the estimated dose delivered to the tumor was 20 Gy (37). A study on pharmacokinetics and dosimetry using ${ }^{111}$ In-1,4,7,10-tetra-azacyclododecan-4,7,10-tri-carboxymethyl-1-yl-D-Phe-Tyr3-octreotide ( ${ }^{111}$ In-DOTA-TOC) to predict the biological behavior of its yttrium-90-labeled counterpart ${ }^{90} \mathrm{Y}$-DOTA-TOC in patients reported an intratumoral radiation dose at 1.4-31 $\mathrm{mGy} / \mathrm{MBq}$ (mean, $10 \mathrm{mGy} / \mathrm{MBq}$ ) (38). A phase I clinical trial on biodistribution and pharmacokinetics of ${ }^{90}$ Y-DOTA-TOC in four cohorts using 122.1, 362.6, 366.3 and $384.8 \mathrm{MBq}$ showed a mean estimated intratumoral dose of $2.1 \mathrm{mGy} / \mathrm{MBq}$ (39). Clinically in hematopoietic disease of non-Hodgkin lymphoma, two FDA-approved products ${ }^{131}$ I-tositumomab and ${ }^{90} \mathrm{Y}$-ibritumomab tiuxetan based on murine antibodies against CD20 B-lymphocyte antigen (CD20) using a single dose of $185 \mathrm{MBq}$ (35 mg) or escalated dosage from 7.4 to 14.8 MBq deposited radiation doses to the tumor around $10 \mathrm{~Gy}$ (40). Altogether these data suggest that OncoCiDia approach seems to be very attractive for treating solid tumors that evolve rapidly to acquire resistance to common targeted therapeutics and require a high cytotoxic dose for getting good therapeutic outcome.
In this study, we also estimated radiation dosimetry of ${ }^{131}$ I-Hyp to normal organs in standard human male and female models from biodistribution data in RPLI rats receiving ${ }^{123} \mathrm{I}-\mathrm{Hyp} / \mathrm{Hyp}$. No statistically significant difference was detected in organ uptake (\%ID) between the genders. However, slightly higher radiation doses $(\mathrm{mGy} / \mathrm{MBq})$ to organs and the body were found for the female model. Although we do not know the exact reasons for such differences, similar results have been reported for other radioactive compounds (41).

Among normal organs, the highest tracer accumulations were mainly detected in the spleen and liver few hours after injection that were quickly removed within one day, as reported (29). Consequently, further dosimetry extrapolations to human models indicated low absorbed radiation doses to such organs, i.e. $\leq 0.68 \mathrm{mGy} / \mathrm{MBq}$ and $\leq 0.28 \mathrm{mGy} / \mathrm{MBq}$ in the spleen and liver, respectively. Indeed, it can be estimated that for an administered activity of $7.4 \mathrm{GBq}$, the radiation dose of ${ }^{131} \mathrm{I}-\mathrm{Hyp}$ delivered to these organs would be below $5 \mathrm{~Gy}$, which is lower than the corresponding maximum tolerated doses (MTD) of 20-45 Gy (42). This administered radioactivity is commonly used for the commercial agent ${ }^{131} \mathrm{I}-\mathrm{MIBG}$ in the treatment of patients with NETs $(5,43)$. Therefore, based on these results we do not expect the signs or symptoms associated with hepatic or splenic dysfunction for radiation overexposure in oncologic patients receiving ${ }^{131} \mathrm{I}-\mathrm{Hyp}$.

Similarly, the acute radiation nephropathy that has been a renal dose (1.65-3.9 mGy/MBq) limiting factor for many other radiotherapeutic agents (44) does not appear risky with OncoCiDia. The lower delivered doses of ${ }^{131} \mathrm{I}$-Hyp to kidneys at $\leq 0.35 \mathrm{mGy} / \mathrm{MBq}$ indicate a minimal uptake and excretion in this radiosensitive organ, which is in agreement with earlier studies (45). Moreover, since the incidence of renal pathological conditions has been highly related to the radionuclide used (44), a reduced risk of radiation-related renal failure may be attributed to the relatively low energy beta particles of ${ }^{131} \mathrm{I}$.

To prevent severe side-effects due to radiation-induced toxicity, another important organ to consider in dosimetry is the brain which is unable to repair itself after an injury. Fortunately, with radioiodinated Hyp, the lowest levels of radioactivity were found in this organ owing to the lowest uptake and the shortest residence time and therefore the lowest values of absorbed radiation dose. In concordance with previous studies (29), ${ }^{131} \mathrm{I}-$ Hyp did not enter the blood-cerebrospinal fluid through the blood-brain barrier (BBB), regardless of its high lipophilicity.

Despite the aforementioned favorable aspects for the safety of OncoCiDia in cancer treatment, dose distribution of the radioiodinated Hyp was found relatively higher in the thyroid, lungs and intestines, which affect the whole-body and organ specific radiation burden and present problems to be solved for the preparation and use of ${ }^{131} \mathrm{I}$-Hyp in OncoCiDia.

Interestingly, in the thyroid gland that is considered a limiting dose organ for ${ }^{131} \mathrm{I}$-labeled product, there was almost no radioactivity concentration related to the presence of free ${ }^{131} \mathrm{I}$ at the earliest time point. However, a progressive increase in radioactivity levels was detected within $24 \mathrm{~h}$, leading to delayed high radiation dose delivered to the gland. Since the radiochemical purity of ${ }^{123} \mathrm{I}-\mathrm{Hyp}$ was greater than $99 \%$ and the carbon-iodine bond has been herein proved to remain stable in vivo $24 \mathrm{~h}$ after administration, we assume that free radioactive iodine was released following hepatobiliary and intestinal metabolism of 
the radioiodinated Hyp and reabsorbed via enterohepatic circulation. Indeed, the occurrence of enterohepatic circulation of the free iodide released in intestines and its eventual accumulation in thyroid has been reported (46). However, it seems that the total amount of circulating ${ }^{131} \mathrm{I}$ after 'recycling' is rather small since it is only detectable in thyroid. Indeed, low radioactivity and short residence were found in other iodine accumulating or excretory organs such as the stomach and kidneys. Nevertheless, the unwanted thyroid irradiation in clinical patients receiving ${ }^{131}$ I-Hyp can be prevented by administration of blocking agents containing cold iodine such as potassium iodide (KI) or sodium perchlorate $\left(\mathrm{NaClO}_{4}\right)(47)$.

A relatively high and persistent radioactivity accumulation was also found in lungs, leading to a moderate absorbed radiation dose to the organ. This is most likely due to the possible entrapment of ${ }^{123} \mathrm{I}-\mathrm{Hyp} / \mathrm{Hyp}$ aggregates by the alveolar macrophages. Several measures can be taken to protect this organ from unnecessary radiation overexposure. Since ${ }^{131} \mathrm{I}-\mathrm{Hyp}$ can be easily prepared with high labelling efficiency $(>95 \%)$, this may allow avoiding purification steps involving aqueous mobile phases that could boost aggregation of poorly water soluble ${ }^{131} \mathrm{I}-\mathrm{Hyp} / \mathrm{Hyp}$ (48). A related toxicity study on the formulation components has suggested the manageable and tolerable safety of the ${ }^{131} \mathrm{I}-\mathrm{Hyp}$ even without purification (49). Furthermore, formulation optimization (50) and the optimized way of injection may reduce aggregation in the preparation and/or body.

Because the amphiphilic radioiodinated Hyp with a molecular weight above $300 \mathrm{~g} / \mathrm{mol}$ is principally excreted via the hepatobiliary pathway, the intestinal toxicity inevitably becomes a limiting factor. High levels of radioactivity were constantly found in intestines and feces from RPLI rats for $48 \mathrm{~h}$. As a consequence, after animal-to-human extrapolation, a high absorbed radiation dose and a long residence time were detected in large intestinal walls. Indeed, these structures along with the thyroid contributed the most to the total body radiation dose obtained for both genders. This may result in an increased risk of developing gastrointestinal syndrome, which is the dominant manifestation after whole body doses of about 6 to $30 \mathrm{~Gy}$ and typically develops within five days of the initial exposure (51). To solve such problems, the suitability of a biliary drainage system to remove the radioactivity excreted into intestines from the body has been investigated with promising results (45).

Regarding highly radiosensitive red marrow, despite the low concentration of radioiodinated Hyp found in the bone, the estimated doses eventually received by this structure were not negligible $(\leq 0.30 \mathrm{mGy} / \mathrm{MBq})$. Indeed, it can be estimated that for an administered activity of $7.4 \mathrm{GBq}$, the absorbed radiation dose of ${ }^{131} \mathrm{I}$-Hyp to red marrow could be around $2.2 \mathrm{~Gy}$, which is slightly higher to that reported for MTD (2 Gy) (52). Contrary to other organs in which the absorbed doses are determined directly, red marrow dosimetry is generally estimated from the blood time-activity curves or whole body doses. With ${ }^{131}$ I-Hyp, it might be possible that the dose derived from whole body due to the high radioactivity accumulation in intestines may negatively impact on the dose delivered to the red marrow. We believe, therefore, by using the duodenal drainage device (45), the red marrow doses can be further reduced.
In conclusion, ${ }^{131} \mathrm{I}$-Hyp is a novel radiopharmaceutical with remarkable affinity for necrotic tissue that provides the possibility of treating most solid cancers by a crossfire effect after treatment with a VDA. In general, its biodistribution and dosimetry are characterized by a high radiation dose delivered to tumor necrosis in contrast with a relative rapid clearance or low absorbed dose in most organs. However, radiosensitive tissues such as thyroid, red marrow, lungs and intestines still receive considerable radiation doses. Several approaches are being developed to address these limitations.

\section{Acknowledgements}

This study was supported in part by the KU Leuven Molecular Small Animal Imaging Center MoSAIC (KUL EF/05/08); the Center of Excellence In vivo Molecular Imaging Research of KU Leuven; KU Leuven project IOF-HB/08/009; and the European Union (Asia-Link CfP 2006-EuropeAid/123738/C/ ACT/Multi-Proposal no. 128-498/111). Y.N. is currently a Bayer Lecture Chair holder.

\section{References}

1. Brown JM: Exploiting the hypoxic cancer cell: mechanisms and therapeutic strategies. Mol Med Today 6: 157-162, 2000.

2. Anderson RT, Linnehan JE, Tongbram V, Keating K and Wirth LJ: Clinical, safety, and economic evidence in radioactive iodine-refractory differentiated thyroid cancer: a systematic literature review. Thyroid 23: 392-407, 2013.

3. McEwan AJ, Amyotte GA, McGowan DG, MacGillivray JA and Porter AT: A retrospective analysis of the cost effectiveness of treatment with Metastron $\left({ }^{89} \mathrm{Sr}\right.$-chloride) in patients with prostate cancer metastatic to bone. Nucl Med Commun 15: 499-504, 1994.

4. Polishchuk AL, Dubois SG, Haas-Kogan D, Hawkins R and Matthay KK: Response, survival, and toxicity after iodine-131-metaiodobenzylguanidine therapy for neuroblastoma in preadolescents, adolescents, and adults. Cancer 117: 4286-4293, 2011.

5. Gedik GK, Hoefnagel CA, Bais E and Olmos RAV: ${ }^{131} \mathrm{I}-\mathrm{MIBG}$ therapy in metastatic phaeochromocytoma and paraganglioma. Eur J Nucl Med Mol Imaging 35: 725-733, 2008.

6. Rhee TK, Lewandowski RJ, Liu DM, et al: ${ }^{90} \mathrm{Y}$ radioembolization for metastatic neuroendocrine liver tumors: preliminary results from a multi-institutional experience. Ann Surg 247: 1029-1035, 2008.

7. Patri P, Pangerl T, Angelberger $\mathrm{P}$, et al: Experience with indium-111 and yttrium-90-labeled somatostatin analogs. Curr Pharm Des 8: 1781-1807, 2002.

8. Kwekkeboom DJ, Kam BL, van Essen M, et al: Somatostatinreceptor-based imaging and therapy of gastroenteropancreatic neuroendocrine tumors. Endocr Relat Cancer 17: R53-R73, 2010.

9. Harrison MR, Wong TZ, Armstrong AJ and George DJ: Radium-223 chloride: a potential new treatment for castrationresistant prostate cancer patients with metastatic bone disease. Cancer Manag Res 5: 1-14, 2013.

10. Jarm T, Cemazar M, Miklavcic D and Sersa G: Antivascular effects of electrochemotherapy: implications in treatment of bleeding metastases. Expert Rev Anticancer Ther 10: 729-746, 2010.

11. Merlo LMF, Pepper JW, Reid BJ and Maley CC: Cancer as an evolutionary and ecological process. Nat Rev Cancer 6: 925-935, 2006.

12. Nowell PC: The clonal evolution of tumor cell populations. Science 194: 23-28, 1976.

13. Katholieke Universiteit Leuven - Oncocidia. http://vimeo. com/44871398.

14. Caraci F, Crupi R, Drago F and Spina E: Metabolic drug interactions between antidepressants and anticancer drugs: focus on selective serotonin reuptake inhibitors and hypericum extract. Curr Drug Metab 12: 570-577, 2011. 
15. Birt DF, Widrlechner MP, Hammer KD, et al: Hypericum in infection: Identification of anti-viral and anti-inflammatory constituents. Pharm Biol 47: 774-782, 2009.

16. Li J, Cona MM, Chen F, Feng Y, Zhou L, Zhang G, Nuyts J, de Witte P, Zhang J, Yu J, Oyen R, Verbruggen A and Ni Y: Sequential systemic administrations of combretastatin A4 phosphate and radioiodinated hypericin exert synergistic targeted theranostic effects with prolonged survival on scid mice carrying bifocal tumor xenografts. Theranostics 3 : $127-137,2013$.

17. Ni Y, Huyghe D, Verbeke K, et al: First preclinical evaluation of mono- $[123]]$ iodohypericin as a necrosis-avid tracer agent. Eur J Nucl Med Mol 33: 595-601, 2006.

18. Fonge $\mathrm{H}$, Vunckx K, Wang $\mathrm{H}$, et al: Non-invasive detection and quantification of acute myocardial infarction in rabbits using mono- $\left[{ }^{123} I\right]$ iodohypericin microSPECT. Eur Heart J 29: 260-269, 2008.

19. Li J, Sun Z, Zhang J, et al: A dual-targeting anticancer approach: soil and seed principle. Radiology 260: 799-807, 2011.

20. Emami B, Lyman J, Brown A, et al: Tolerance of normal tissue to therapeutic irradiation. Int J Radiat Oncol Biol Phys 21: 109-122, 1991

21. Ni Y, Adzamli K, Miao Y, et al: MRI contrast enhancement of necrosis by MP-2269 and Gadophrin-2 in a rat model of liver infarction. Invest Radiol 36: 97-103, 2001.

22. Stabin MG, Sparks RB and Crowe E: OLINDA/EXM: the second-generation personal computer software for internal dose assessment in nuclear medicine. J Nucl Med 46: 1023-1027, 2005.

23. Howard DM, Kearfott KJ, Wilderman SJ and Dewaraja YK: Comparison of I-131 radioimmunotherapy tumor dosimetry: unit density sphere model versus patient-specific Monte Carlo calculations. Cancer Biother Radiopharm 26: 615-621, 2011.

24. Tipre DN, Lu JQ, Fujita M, Ichise M, Vines D and Innis RB: Radiation dosimetry estimates for the PET serotonin transporter probe ${ }^{11} \mathrm{C}$-DASB determined from whole-body imaging in nonhuman primates. Nucl Med Commun 25: 81-86, 2004.

25. Stabin MG, Tagesson $M$, Thomas SR, Ljungberg $M$ and Strand SE: Radiation dosimetry in nuclear medicine. Appl Radiat Isot 50: 73-87, 1999.

26. Van Laere K, Koole M, Sanabria Bohorquez SM, et al: Whole-body biodistribution and radiation dosimetry of the human cannabinoid type-1 receptor ligand ${ }^{18} \mathrm{~F}-\mathrm{MK}-9470$ in healthy subjects. J Nucl Med 49: 439-445, 2008.

27. Monsieurs M, Brans B, Bacher K, Dierckx R and Thierens H: Patient dosimetry for ${ }^{131} \mathrm{I}-\mathrm{MIBG}$ therapy for neuroendocrine tumors based on ${ }^{123}$ I-MIBG scans. Eur J Nucl Med Mol Imaging 29: $1581-1587,2002$

28. Phinou PC, Lyra M, Jordanou J, Pappas D, Limouris G and Vlahos L: Patient-specific dosimetry of I-131-MIBG therapy of adrenal tumours using I-123-MIBG diagnostic imaging. World J Nucl Med 5: 8, 2006.

29. Cona MM, Li J, Feng Y, Chen F, Verbruggen A, de Witte P, Oyen $\mathrm{R}$ and Ni Y: Targetability and biodistribution of radioiodinated hypericin: comparison between microdosing and carrier-added preparations. Anticancer Agents Med Chem: Aug 28, 2013 (Epub ahead of print).

30. Li J, Cona MM, Chen F, et al: Exploring theranostic potentials of radioiodinated hypericin in rodent necrosis models. Theranostics 2: 1010-1019, 2012.

31. Loke KS, Padhy AK, Ng DC, Goh AS and Divgi C: Dosimetric considerations in radioimmunotherapy and systemic radionuclide therapies: a review. World J Nucl Med 10: 122-138, 2011.

32. Ferro-Flores G and de Murphy CA: Pharmacokinetics and dosimetry of ${ }^{188} \mathrm{Re}$-pharmaceuticals. Adv Drug Deliver Rev 60: 1389-1401, 2008.

33. Asghar S, Sajjad R and Illyas N: Role of high dose I-131 in treatment of differentiated thyroid carcinoma: An experience of 354 patients at INMOL. In: Therapeutic Applications of Radiopharmaceuticals. International Atomic Energy Agency, Vienna, pp155-157, 2001

34. Chen FM, Taylor CR and Epstein AL: Tumour necrosis treatment of ME-180 human cervical carcinoma model with ${ }^{131} \mathrm{I}$-labeled TNT-1 monoclonal antibody. Cancer Res 49: 4578-4585, 1989.
35. Persson M, Rasmussen P, Madsen J, Ploug $M$ and Kjaer A: New peptide receptor radionuclide therapy of invasive cancer cells: in vivo studies using ${ }^{177} \mathrm{Lu}$-DOTA-AE105 targeting uPAR in human colorectal cancer xenografts. Nucl Med Biol 39: 962-969, 2012

36. Persson M, Gedda L, Lundqvist $H$, Tolmachev V, Nordgren $H$, Malmström PU and Carlsson J: [ $\left.{ }^{177} \mathrm{Lu}\right]$ pertuzumab: experimental therapy of HER-2-expressing xenografts. Cancer Res 67: 326-331, 2007.

37. Seo Y, Gustafson WC, Dannoon SF, et al: Tumor dosimetry using [(124)I]m-iodobenzylguanidine microPET/CT for [(131) I]m-iodobenzylguanidine treatment of neuroblastoma in a murine xenograft model. Mol Imaging Biol 14: 735-742, 2012.

38. Cremonesi M, Bodei M, Rocca P, Stabin M, Maecke H and Paganelli G: Kidney protection during receptor-mediated radiotherapy with ${ }^{90} \mathrm{Y}$-[DOTA0, Tyr3] octreotide. Cancer Biother Radiopharm 17: 344, 2002.

39. Jamar F, Barone R, Mathieu I, et al: 86Y-DOTA(0)-DPhe1Tyr3-octreotide (SMT487) - a phase 1 clinical study: pharmacokinetics, biodistribution and renal protective effect of different regimens of amino acid co-infusion. Eur J Nucl Med Mol Imaging 30: 510-518, 2003.

40. Kaminski MS, Estes J, Zasadny KR, et al: Radioimmunotherapy with iodine ${ }^{131}$ I tositumomab for relapsed or refractory B-cell non-Hodgkin lymphoma: updated results and long-term follow-up of the University of Michigan experience. Blood 96: 1259-1266, 2000.

41. Comley RA, Salinas C, Mizrahi R, et al: Biodistribution and radiation dosimetry of the serotonin $5-\mathrm{HT}_{6}$ ligand $\left[{ }^{11} \mathrm{C}\right]$ GSK215083 determined from human whole-body PET. Mol Imaging Biol 14: 517-521, 2012.

42. Kassis AI and Adelstein J: Considerations in the selection of radionuclides for cancer therapy. In: Handbook of Padiopharmaceuticals, Padiochemistry and Applications. Welch MJ and Redvanly CS (eds). Wiley \& Sons, London, p93, 2003.

43. Lam MG, Lips CJ, Jager PL, Dullaart RP, Lentjes EG, van Rijk PP and de Klerk JM: Repeated $\left.{ }^{[131} I\right]$ metaiodobenzylguanidine therapy in two patients with malignant pheochromocytoma. J Clin Endocrinol Metab 90: 5888-5895, 2005.

44. Lam MG, Lips CJ, Jager PL, Dullaart RP, Lentjes EG, van Rijk PP and de Klerk JM: Clinical radionuclide therapy dosimetry: the quest for the 'Holy Gray'. Eur J Nucl Med Mol Imaging 34: 772-786, 2007.

45. Cona MM, Feng Y, Verbruggen A, Oyen R and Ni Y: Improved clearance of radioiodinated hypericin as a targeted anticancer agent by using a duodenal drainage catheter in rats. Exp Biol Med (Maywood): Oct 21, 2013 (Epub ahead of print).

46. Berson SA and Yalow RS: Quantitative aspects of iodine metabolism. The exchangeable organic iodine pool, and the rates of thyroidal secretion, peripheral degradation and fecal excretion of endogenously synthesized organically bound iodine. J Clin Invest 33: 1533-1552, 1954

47. Hänscheid H, Reiners C, Goulko G, et al: Facing the nuclear threat: thyroid blocking revisited. J Clin Endocrinol Metab 96: 3511-3516, 2011.

48. Liu G, Dou S, He J, et al: Radiolabeling of MAG3-morpholino oligomers with ${ }^{188} \mathrm{Re}$ at high labeling efficiency and specific radioactivity for tumor pre-targeting. Appl Radiat Isot 64: 971-978, 2006.

49. Cona MM, Li J, Chen F, et al: A safety study on single intravenous dose of tetrachloro-diphenyl glycoluril [iodogen] disolved in dimethyl sulphoxide (DMSO). Xenobiotica 43: 730-737, 2013.

50. Cona MM, Alpizar YA, Li J, et al: Radioiodinated hypericin: its biodistribution, necrosis avidity and therapeutic efficacy are influenced by formulation. Pharm Res: Aug 9, 2013 (Epub ahead of print).

51. Saha S, Bhanja P, Liu L, et al: TLR9 agonist protects mice from radiation-induced gastrointestinal syndrome. PLoS One 7: e29357, 2012.

52. De Keizer B, Hoekstra A, Konijnenberg MW, et al: Bone marrow dosimetry and safety of high ${ }^{131}$ I activities given after recombinant human thyroid-stimulating hormone to treat metastatic differentiated thyroid cancer. J Nucl Med 45: 1549-1554, 2004. 